\title{
Lack of effect of sublingual salvinorin A, a naturally occurring kappa opioid, in humans: a placebo-controlled trial
}

\author{
John E. Mendelson • Jeremy R. Coyle • Juan Carlos Lopez • Matthew J. Baggott • \\ Keith Flower • E. Thomas Everhart • Thomas A. Munro • Gantt P. Galloway • \\ Bruce M. Cohen
}

Received: 13 August 2010 / Accepted: 12 November 2010 /Published online: 8 December 2010

(C) The Author(s) 2010 This article is published with open access at Springerlink.com

\begin{abstract}
Rationale Salvinorin A (SA) is a highly selective kappa opioid receptor agonist and the putative psychoactive compound in Salvia divinorum (SD), an increasingly abused hallucinogenic plant.

Objectives The objectives of this study were to characterize the physiological and subjective effects of SA versus placebo and measure drug and metabolite levels.

Methods Sublingual SA doses up to $4 \mathrm{mg}$ were administered in dimethyl sulfoxide/polyethylene glycol 400 solution to eight SD-experienced subjects using a placebo-controlled ascending-dose design.

Results No dose of SA produced significantly greater physiological or subjective effects than placebo. Furthermore, effects did not resemble reported "typical" effects of smoked SD. SA was detectable in plasma and urine, but was, in most cases, below the reliable limit of quantification $(0.5 \mathrm{ng} / \mathrm{mL})$.
\end{abstract}

J. E. Mendelson · J. R. Coyle · J. C. Lopez $(\bowtie) \cdot$ M. J. Baggott •

K. Flower $\cdot$ G. P. Galloway

Addiction and Pharmacology Research Laboratory, California

Pacific Medical Center Research Institute,

San Francisco, CA, USA

e-mail: lopez.juan.c@gmail.com

E. T. Everhart

Department of Psychiatry, UCSF,

San Francisco, CA, USA

T. A. Munro $\cdot$ B. M. Cohen

Department of Psychiatry, Harvard Medical School,

Cambridge, MA, USA

T. A. Munro $\cdot$ B. M. Cohen

McLean Hospital,

Belmont, MA, USA
Conclusions Our results suggest that the sublingual bioavailability of SA is low. Higher doses, alternate formulations, or alternate routes of administration will be necessary to study the effects of SA in humans.

Keywords Salvia divinorum · Salvinorin A · Kappa opioid receptor $\cdot$ Sublingual administration

\section{Introduction}

An estimated 1.8 million Americans have tried Salvia divinorum (SD), a psychoactive mint that traditionally had been used for divination and healing in the Mazatec region of Mexico (Substance Abuse and Mental Health Services Administration 2006). SD use is also occurring in Europe (Pavarin 2006) and Japan (Tsujikawa et al. 2008), and SD is sold in smoke shops and over the web in preparations with often inaccurately labeled and varying strength (Wolowich et al. 2006). The psychoactive agent in $S$. divinorum is believed to be salvinorin A (SA), a trans-neoclerodane diterpenoid (Ortega et al. 1982; Valdés et al. 1984). Siebert reported that when administered to humans by vaporization and inhalation, SA is psychoactive with effects substantially similar to those of the whole leaf (Siebert 1994). A recent placebo-controlled trial confirmed this, reporting intense self-rated and observer-rated effects from a smoked dose of $1 \mathrm{mg}$ SA (Addy 2010). Several animal studies have also confirmed the psychoactivity of SA (Butelman et al. 2004; Carlezon et al. 2006; Fantegrossi et al. 2005; Valdés et al. 1987). SA is the first known naturally occurring selective kappa opioid and may be the most potent naturally occurring hallucinogen (Roth et al. 2002). Limited clinical studies suggest kappa opioids induce effects, including dysphoria, 
hallucinations, and dissociation (Walsh et al. 2001). Although reported effects of SD appear brief and range from laughter to depersonalization (González et al. 2006), a few reports raise the question of possibly persisting neuropsychiatric effects (i.e. paranoia, psychosis) (Breton et al. 2010; Paulzen and Grunder 2008; Przekop and Lee 2009). One case report of paranoia and cognitive impairment sometimes attributed to SD appears to have been caused by marijuana, illustrating the difficulties of defining psychoactive effects without controlled trials (Singh 2007).

Anecdotal reports suggest that SD produces strong effects when taken orally (Valdés 1983) or when held in the mouth (Siebert 1994), but there have been conflicting reports on sublingual absorption of pure SA. Psychoactivity has been reported from sublingual doses as low as $100 \mu \mathrm{g}$ (Ott 1996), but in other reports, no consistent effects have been seen at doses up to $2 \mathrm{mg}$ (Siebert 1994) or even $12 \mathrm{mg}$ (Zhah 2009).

Most SA users smoke the drug (Baggott et al. 2010; González et al. 2006); however, due to individual differences in smoking technique, peculiarities of smoking apparatuses, and losses of drug to combustion, determining the delivered dose of a smoked drug can be difficult or impossible. In addition, maximal psychoactive effects can occur almost immediately after smoked drug delivery, decreasing the ability to assess and document effects on the ascending limb of the dose-response function. In contrast to the typical smoked administration, which produces rapid, brief, and intense effects, we sought to produce effects that would be less intense, better controlled, and more easily measurable (by virtue of their increased duration: an estimated 45-60 min (Baggott et al. 2010). We therefore administered SA sublingually to attain a slower onset (relative to smoking) and standardize dose delivery. This study reports on the first laboratorybased, dose-controlled study on the effects of SA in humans.

\section{Methods}

\section{Study design}

An ascending-dose $(0-4,000 \mu \mathrm{g}$ SA, sublingual), placebo-controlled design in eight SD-experienced subjects was used. To be included, subjects had to be between the ages of 21 and 45; healthy as determined by medical history, mental status, and physical examinations, laboratory tests of renal and hepatic function; and have at least three self-reported SD experiences with and no adverse reactions to SD or hallucinogen use. Subjects were excluded for dependence on any illicit drug or alcohol.
Sublingual doses ranged from 0 to $4,000 \mu \mathrm{g}$. This dose range was selected based on a review of likely doses taken recreationally (Ott 1995; 1996; Siebert 1994) and with the goal of producing (at most) modest pharmacological effects in humans. Dosing sessions were separated by at least $24 \mathrm{~h}$. The first two doses (placebo and $100 \mu \mathrm{g}$ ) were doubleblind; the remaining five doses $(250,500,1,000,2,000$, and $4,000 \mu \mathrm{g}$ ) were single-blind. The predetermined stopping criteria for dose escalation were a Visual Analog Scale (VAS) "Intoxication" rating above $50 \%$, a self-report indication that the previous dose was not tolerable, or clinically significant cardiovascular, neurological, or psychiatric symptoms as determined by the study physician. The study was approved by the California Pacific Medical Center Institutional Review Board, and an Investigational New Drug Exemption was obtained from the US Food and Drug Administration.

\section{Dose preparation}

SA was isolated from dried commercial SD leaves (Bouncing Bear Botanicals, Lawrence, KS) as previously described (Munro and Rizzacasa 2003). Proton nuclear magnetic resonance (300 MHz) and liquid chromatography (LC)-mass spectrometry (MS) was consistent with past results (Munro and Rizzacasa 2003) and showed no detectable impurities. SA was soluble in $25 \%$ dimethyl sulfoxide (DMSO)/75\% polyethylene glycol 400 (PEG-400) at $4,000 \mu \mathrm{g} / \mathrm{mL}$ and was stable for 6 days, as determined by LC-MS/MS, with only trace amounts of the hydrolysis product salvinorin $\mathrm{B}(\mathrm{SB})$ forming.

Doses were prepared by a research pharmacist. A $500-\mu \mathrm{g} / \mathrm{mL}$ SA solution was made in ethyl acetate; appropriate doses were pipetted into scintillation vials, then evaporated to dryness, and stored in a cool, dry location. Doses were prepared by redissolving the SA in $1 \mathrm{~mL}$ of a slightly viscous mixture of $25 \%$ DMSO/75\% PEG-400; both were USP grade (Coyerly et al. 1998).

Sublingual dosing procedure

SA in the DMSO/PEG-400 vehicle or the DMSO/PEG-400 placebo was administered sublingually with a needle-less syringe. Subjects were instructed to hold the liquid without swallowing for $5 \mathrm{~min}$ and were monitored for adherence. After $5 \mathrm{~min}$, subjects expectorated mouth contents into a container for disposal then rinsed with $60 \mathrm{~mL}$ water before swallowing.

Safety monitoring and outcome measures

Subjects were continually monitored for signs and symptoms of toxicity until $4 \mathrm{~h}$ post-dose. Heart rate, blood 
pressure, and oxygen $\left(\mathrm{O}_{2}\right)$ saturation were measured with a Philips C3 Patient Monitor and core temperature with an ingested monitor (Minimitter Vitalsense) at baseline and $0.25,0.5,0.75,1,2$, and $4 \mathrm{~h}$ post-dose. Plasma samples for SA levels were obtained at $20 \mathrm{~min}$, and all of the urine was collected for the $4 \mathrm{~h}$ post-dose.

Assay for salvinorin $A$ and $B$ A sensitive and specific liquid-chromatographic-atmospheric pressure chemical ionization-tandem mass spectrometric (LC-APCI-MS/MS) method was developed to measure SA and its primary metabolite, $\mathrm{SB}$, in human plasma and urine (see Appendix). The C-4 trideuteromethyl ester analogs of the analytes were utilized as the internal standards. The limits of quantitation were $0.5 \mathrm{ng} / \mathrm{mL}$ for both $\mathrm{SA}$ and $\mathrm{SB}$ in plasma and urine.

Visual Analog Scales Two VAS questionnaires, anchored with "not at all" to "extremely," were obtained. One questionnaire ("any drug effect," "good drug effect," "bad drug effect," "high," "stimulated," "clear-headed," "sedated," “confused," “drunken," “insightful," "closeness to others," and "intoxication") was obtained at the same times as physiological measures. The second questionnaire ("Feelings of unreality," "Difficulty controlling thoughts," "Size, depth, or shape of my surroundings seems changed," "My body or body parts seem changed," "The passing of time seems changed," "Familiar things seem unfamiliar," "Some events, objects, or other people have new meanings for me," "Suspicious feelings that others might be against me," "When I close my eyes, I see complex abstract patterns," "When I close my eyes, I see objects or nonliving things," "When I close my eyes, I see animals, people, or beings," and "When I close my eyes, I see places or landscapes") was obtained $2 \mathrm{~h}$ post-dose with subjects answering for the time since dosing. During screening, subjects were asked to rate their "typical" SA experience on both VAS questionnaires.

The Subjective Drug Effects Questionnaire (SDEQ), Altered States of Consciousness Questionnaire (APZ-OAV), and Positive and Negative Affect Schedule (PANAS) were administered between 2 and $4 \mathrm{~h}$ post-dose to broadly characterize subjective symptoms typically altered by hallucinogens. The SDEQ is a 272-item drug effects questionnaire that was originally developed to distinguish LSD from D-amphetamine and has subsequently been used to characterize a variety of drug classes (Harris et al. 2002; Katz et al. 1968; Snyder et al. 1968; Turek et al. 1974). The APZ-OAV is a 94-item questionnaire widely used in European studies of hallucinogen-like compounds (Dittrich 1998). The 20-item PANAS is widely used in psychological and pharmacological studies to measure positive and negative affect (Watson et al. 1988).

\section{Results}

Eight subjects (5 Caucasian men, 1 Caucasian woman, 1 Asian man, and 1 Asian woman) with an average age of 31 years (range, 21-45) received SA in this study. Subjects reported a mean of 10 (range, 3-40) previous uses of SD and reported experiencing "strong effects" an average of six times (range, 2-20). One subject reported using SD in the 90 days before study entry, and two more reported using it in the year before study entry. Therefore, tolerance to SA among our subjects was unlikely. All subjects reported abstinence from prescribed or recreational opiate agonists for at least 90 days before study entry. Because no subject met the stopping criteria, each subject was given all dose levels of SA.

SA did not affect pulse, blood pressure, $\mathrm{O}_{2}$ saturation, or core temperature. In general, no subjects reported effects similar in quality or magnitude to their reported "typical" SA exposures. There was no effect of dose on responses to the SDEQ, APZ-OAV, PANAS, or most VAS items. VAS scores for "headache" and "insightful" items decreased relative to placebo, but effects were small and inconsistent between doses. Only two male subjects reported VAS “intoxication" scores above 25: both occurred $15 \mathrm{~min}$ after the $1,000 \mu \mathrm{g}$ dose. In contrast, subject's ratings of "typical" SA experiences using the VAS (Fig. 1) and APZ-OAV measures were significantly different from, and, in general, higher than, ratings for both placebo and the 4,000 $\mu \mathrm{g}$ dose. Because of the low intoxication ratings reported, we only assayed blood and urine samples from the highest $(4,000 \mu \mathrm{g})$ dose and the two cases where intoxication scores were higher than 25 . Most SA concentrations were below the limit of quantification (Table 1).

\section{Discussion}

Sublingual doses of $4,000 \mu \mathrm{g}$ SA did not produce even mild effects. Scores on the VAS and APZ-OAV measures indicated that the subjective experience of $4,000 \mu \mathrm{g}$ failed to differ significantly from placebo and was significantly lower than scores for "typical" effects.

The lack of subjective effects and the low levels of SA in blood and urine suggest that the sublingual bioavailability of SA is poor. This is consistent with earlier anecdotal reports that sublingual doses of up to $2 \mathrm{mg}$ (Siebert 1994) or $12 \mathrm{mg}$ (Zhah 2009) produced no consistent effect, and cast doubt on claims of detectable effects at doses as low as $100 \mu \mathrm{g}$ (Ott 1995).

One possible factor in these discrepancies is the different solvents used. We used 25\% DMSO/PEG-400, while earlier reports have employed ethanol (Siebert 1994), DMSO (Ott 
When I close my eyes, I see complex abstract patterns Size, depth, or shape of my surroundings seems changed Feelings of unreality The passing of time seems changed Insightful Good Drug Any Drug Stimulated Some events, objects, or other people have new meanings for me Difficulty controlling thoughts Confused

Familiar things seem unfamiliar When I close my eyes, I see places or landscapes When I close my eyes, I see objects or non-living things Closeness to others When I close my eyes, I see animals, people, or beings Intoxication

My body or body parts seem changed Nervous Lethargy

Suspicious feelings that others might be against me Drunken Headache Bad Drug Nausea

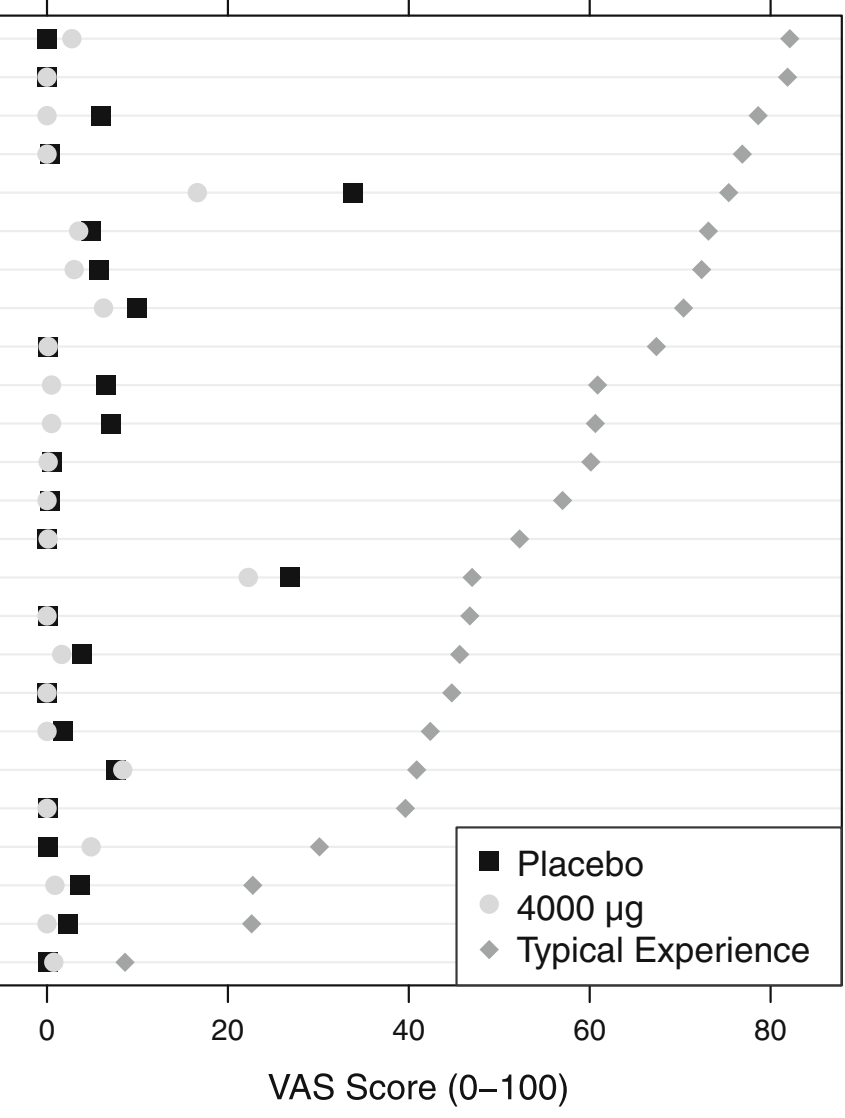

Fig. 1 Four milligrams of salvinorin A had minimal subjective effects: each point indicates the mean VAS score for peak effects after 4 mg dose (circle), peak effects after placebo (square), and "typical" experience (diamond)

1995), or acetone (Ott 1995; Zhah 2009). SA may have greater bioavailability in certain solvents. However, two prior reports using acetone gave conflicting results, suggesting that choice of vehicle does not fully account for the discrepancy. DMSO, ethanol, and acetone are all irritants, making controlled trials using these solvents difficult.

There are many reports of psychoactivity when SD is taken by chewing the leaves or holding an infusion or tincture in the mouth (Ott 1995; Siebert 1994). Similarly, in early animal studies, crude SD extracts showed higher potency than pure SA. However, no other active constituent has been isolated from SD (Munro 2006), suggesting that other compounds in SD may enhance the absorption of SA. A similar effect occurs with the isoflavone daidzin, whose bioavailability is enhanced tenfold in a crude plant extract (Keung et al. 1996). Thus, future work might test SD tinctures containing standardized levels of SA rather than the pure compound.
Table 1 Urine and plasma salvinorin levels $(\mathrm{ng} / \mathrm{mL})$
Dash indicates not determined. Blank cells indicate values $<0.5 \mathrm{ng} / \mathrm{mL}$

\begin{tabular}{|c|c|c|c|c|c|c|c|}
\hline \multirow[t]{2}{*}{ Subject } & \multirow[t]{2}{*}{ Age } & \multirow[t]{2}{*}{ Gender } & \multirow[t]{2}{*}{ Dose $(\mu \mathrm{g})$} & \multicolumn{2}{|c|}{ Plasma } & \multicolumn{2}{|l|}{ Urine } \\
\hline & & & & SA & SB & SA & SB \\
\hline 3 & 30 & M & 1,000 & & & & \\
\hline 4 & 24 & M & 1,000 & & & & 0.665 \\
\hline 1 & 24 & $\mathrm{M}$ & 4,000 & & & & 0.484 \\
\hline 2 & 39 & M & 4,000 & & & - & - \\
\hline 3 & 30 & M & 4,000 & 0.338 & 0.921 & - & - \\
\hline 4 & 24 & M & 4,000 & & & & 1.214 \\
\hline 5 & 21 & $\mathrm{M}$ & 4,000 & & & & \\
\hline 6 & 45 & M & 4,000 & 0.52 & & & 0.295 \\
\hline 7 & 24 & F & 4,000 & & & 0.119 & 0.57 \\
\hline 8 & 40 & F & 4,000 & 0.672 & & & 0.874 \\
\hline
\end{tabular}


In conclusion, in this first controlled study of the effects of SA in human subjects, sublingual doses up to $4,000 \mu \mathrm{g}$ in DMSO/PEG-400 were not psychoactive. These results suggest that the sublingual bioavailability of pure SA is low and that oral absorption of SA from SD depends on other components of SD or the local effects of SD on conditions in the mouth.

Acknowledgements The authors wish to thank Margie Jang for her assistance with data collection.

Contributors Baggott, Cohen, Galloway, Mendelson, and Munro designed the protocol. Coyle, Everhart, Flower, Galloway, Lopez, and Mendelson implemented the study procedures. Munro isolated the salvinorin A and wrote the discussion of solvent and formulation effects. Coyle conducted the statistical analyses and wrote the first draft of the manuscript. All authors contributed to and approved the final manuscript.

Role of funding source This study was supported by a grant from an anonymous donor. Baggott received support from the Beckley Foundation. These sources had no further role in study design; in the collection, analysis, and interpretation of data; in the writing of the report; or in the decision to submit the paper for publication.

Conflicts of interest We have no conflicts of interest to declare.

Open Access This article is distributed under the terms of the Creative Commons Attribution Noncommercial License which permits any noncommercial use, distribution, and reproduction in any medium, provided the original author(s) and source are credited.

\section{Appendix}

\section{Method for determination of salvinorins $A$ and $B$ in DMSO/PEG-400 by APCI LC/MS/MS}

Sample preparation

Two solutions of salvinorin A were prepared at a concentration of $4.00 \mathrm{mg} / \mathrm{mL}$ in DMSO-PEG-400 $(25: 75, v / v)$. One was prepared and allowed to sit on the laboratory benchtop at room temperature for 6 days, while the other was prepared just before sample analysis. Just before analysis, $100 \mu \mathrm{L}$ of each solution was dissolved in $9.90 \mathrm{~mL}$ of ethyl acetate to provide two $10-\mathrm{mL}$ solutions at concentrations of $40 \mu \mathrm{g} / \mathrm{mL}$.

Calibration standards were prepared by spiking mixtures of salvinorin A and B in the following amounts in $16 \times$ $100 \mathrm{~mm}$ silanized screw-top culture tubes: $0,10,50,100$, $250,500,750,1,000$, and 2,000 ng/mL. Quality control
(QC) samples were prepared in duplicate at the following concentrations: 50,250 , and $1,000 \mathrm{ng} / \mathrm{mL}$. Each tube also contained a mixture of the internal standards, salvinorin A 4- $\mathrm{CO}_{2} \mathrm{CD}_{3}$ and salvinorin $\mathrm{B} 4-\mathrm{CO}_{2} \mathrm{CD}_{3}$, in the amount of $2,000 \mathrm{ng}$ each.

Twenty-five microliters $(1,000 \mu \mathrm{g})$ of the ethyl acetate dilutions of the DMSO-PEG400 solutions were transferred to $16 \times 100 \mathrm{~mm}$ silanized screw-top culture tubes, which had been supplemented with 2,000 ng of each of the internal standards. These samples were prepared in duplicate.

\section{Extraction and derivatization}

To each tube was added $1 \mathrm{~mL}$ of water and $4 \mathrm{~mL}$ of an ethyl acetate-heptane $(1: 3, v / v)$ mixture. The tubes were vortex-mixed for $5 \mathrm{~min}$ and centrifuged at 3,000 rpm for $5 \mathrm{~min}$. The aqueous layer was frozen in a dry ice-acetone bath, the organic layer decanted into a clean, silanized tube, and the solvent evaporated in the centrifugal evaporator. To each tube was added $100 \mu \mathrm{L}$ of a $5 \%(v / v)$ solution of acetic anhydride- $d_{6}$ in methylene chloride $\left(\mathrm{CH}_{2} \mathrm{Cl}_{2}\right)$ and $100 \mu \mathrm{L}$ of $0.5 \%(w / v) ~ N, N$-dimethylaminopyridine in $\mathrm{CH}_{2} \mathrm{Cl}_{2}$. The tubes were capped and vortex-mixed for $2 \mathrm{~h}$, and the reaction mixtures quenched by the addition of $1 \mathrm{~mL}$ of methanol and vortex mixing for another $5 \mathrm{~min}$. After evaporation of the solvent the residue was partitioned between $4 \mathrm{~mL}$ of an ethyl acetate-heptane $(4: 1, v / v)$ mixture and $0.5 \mathrm{~mL}$ of $0.25 \mathrm{M}$ sulfuric acid. Vortex-mixing for $5 \mathrm{~min}$ was followed by centrifuging for $5 \mathrm{~min}$, freezing of the aqueous layer, decanting of the organic layer into a clean tube, and evaporation to dryness in the centrifugal evaporator. The residues were reconstituted in $200 \mu \mathrm{L}$ of $\mathrm{MeOH}$, filtered through $0.45 \mu \mathrm{m}$ filters, and transferred to $200 \mu \mathrm{L}$ autosampler vial inserts. The inserts were placed in vials, capped, and loaded onto the autosampler tray.

\section{Liquid chromatography}

LC analyses were performed on a Thermo Separation Products P4000 gradient pump. Separations were achieved on a Phenomenex Synergi Polar $(4.6 \times 150 \mathrm{~mm}, 4 \mu \mathrm{m}$ particle size) reversed-phase HPLC column employing $0.1 \%$ formic acid and methanol as the mobile phase components. The solvents were degassed before use, employing a Thermo Separation Products SCM1000 vacuum degasser equipped with the optional helium sparging module. The column was protected by the use of two Phenomenex Security Guard cartridges installed in tandem with the analytical column. The flow rate was $1 \mathrm{~mL} / \mathrm{min}$. Analyses were carried out with a linear gradient of $0.1 \%$ formic acid-methanol $(50: 50, v / v)$ to $100 \%$ methanol over a 
period of $15 \mathrm{~min}$. All solvents were degassed before use by sparging with helium.

\section{Mass spectrometry}

Mass spectrometric data was acquired with a Finnigan TSQ7000 triple-stage-quadrupole instrument fitted with an APCI API2 probe and interfaced with an APCI/ESI controller unit. The vaporizer and heated capillary temperatures were maintained at $450^{\circ} \mathrm{C}$ and $150^{\circ} \mathrm{C}$, respectively, and the corona voltage was set at $4 \mathrm{kV}$. The nitrogen sheath gas pressure was $60 \mathrm{psi}$; however, the auxiliary gas function was not used. The low mass (0-2,000 amu) range was selected. For recording data in the fullscan mode, the mass spectrometer was scanned from 100 to $650 \mathrm{amu}$ with a scan time of $0.5 \mathrm{~s}$. For MS/MS analyses, the argon gas pressure in the collision cell was set to 2.6 mTorr. Quantitative analyses were carried out in the selected reaction monitoring mode, with the following transitions being monitored: $\mathrm{m} / \mathrm{z} 433$ to $\mathrm{m} / \mathrm{z} 373$ for salvinorin A; $\mathrm{m} / \mathrm{z} 436$ to $\mathrm{m} / \mathrm{z} 373$ for salvinorin $\mathrm{B} ; \mathrm{m} / \mathrm{z} 436$ to $\mathrm{m} / \mathrm{z} 376$ for salvinorin $\mathrm{A}-\mathrm{d}_{3}$; and $\mathrm{m} / \mathrm{z} 439$ to $\mathrm{m} / \mathrm{z} 376$ for salvinorin B- $d_{3}$. The resolution was set to $0.6 \mathrm{amu}$ and the scan times to $0.25 \mathrm{~s}$. The collision energy for each transition was $15 \mathrm{~V}$.

\section{Prepared dose stability testing}

Finnigan Xcalibur/LC Quan software was used to generate the calibration curves (non-linear regression, 1/X weighting) and calculate concentrations using peak-height ratios of analyte/ internal standard. Standard curves were generated from 0 to 2,000 ng/mL.

A concentration of salvinorin A in DMSO-PEG-400 $(25: 75, v / v)$ of $4.00 \mathrm{mg} / \mathrm{mL}$ should calculate to $1,000 \mathrm{ng} /$ $\mathrm{mL}$. The following results were obtained:

Found concentration $(\mathrm{ng} / \mathrm{mL}) \quad$ Equivalent concentration in DMSO-PEG $400(\mathrm{ng} / \mathrm{mL})$

Freshly prepared solution
$\begin{array}{lll}1 . & 915 & 3.66 \\ 2 . & 915 & 3.66 \\ \text { Six-day-old solution } & \\ \text { 1. } \quad 891 & 3.56 \\ \text { 2. } \quad 894 & 3.59\end{array}$

The results of the analyses indicate a $1 \%$ difference between the calculated values for the two sets of samples, which is statistically insignificant. The analyses also detected trace amounts of the hydrolysis product, salvinorin $\mathrm{B}$, in both samples.

\section{References}

Addy PH (2010) That deep internal voice: controlled administration of Salvia divinorum clinical psychology. Institute of Transpersonal Psychology, Palo Alto

Baggott MJ, Erowid E, Erowid F, Galloway GP, Mendelson J (2010) Use patterns and self-reported effects of Salvia divinorum in 500 users. Drug Alcohol Depend 111:250-256

Breton J, Huynh C, Raymond S, Labelle R, Bonnet N, Cohen D, Guilé J (2010) Prolonged hallucinations and dissociative self mutilation following use of Salvia divinorum in a bipolar adolescent girl. J Subs Use 15:113-117

Butelman ER, Harris TJ, Kreek MJ (2004) The plant-derived hallucinogen, salvinorin A, produces kappa-opioid agonist-like discriminative effects in rhesus monkeys. Psychopharmacology (Berl) 172:220-224

Carlezon WA Jr, Beguin C, DiNieri JA, Baumann MH, Richards MR, Todtenkopf MS, Rothman RB, Ma Z, Lee DY, Cohen BM (2006) Depressive-like effects of the kappa-opioid receptor agonist salvinorin A on behavior and neurochemistry in rats. J Pharmacol Exp Ther 316:440-447

Coyerly J, Peters L, Whittle E, Basketter DA (1998) Susceptibility to skin stinging, non-immunologic contact urticaria and acute skin irritation; is there a relationship? Wiley, New York, pp 90-95

Dittrich A (1998) The standardized psychometric assessment of altered states of consciousness (ASCs) in humans. Pharmacopsychiatry 31(Suppl 2):80-84

Fantegrossi WE, Kugle KM, Valdes LJ III, Koreeda M, Woods JH (2005) Kappa-opioid receptor-mediated effects of the plantderived hallucinogen, salvinorin A, on inverted screen performance in the mouse. Behav Pharmacol 16:627-633

González D, Riba J, Bouso JC, Gómez-Jarabo G, Barbanoj MJ (2006) Pattern of use and subjective effects of Salvia divinorum among recreational users. Drug Alcohol Depend 85:157-162

Harris DS, Baggott M, Mendelson JH, Mendelson JE, Jones RT (2002) Subjective and hormonal effects of 3, 4methylenedioxymethamphetamine (MDMA) in humans. Psychopharmacology (Berl) 162:396-405

Katz MM, Waskow IE, Olsson J (1968) Characterizing the psychological state produced by LSD. J Abnorm Psychol 73:1-14

Keung WM, Lazo O, Kunze L, Vallee BL (1996) Potentiation of the bioavailability of daidzin by an extract of Radix puerariae. Proc Natl Acad Sci USA 93:4284-4288

Munro TA (2006) The chemistry of Salvia divinorum chemistry. University of Melbourne, Melbourne

Munro TA, Rizzacasa MA (2003) Salvinorins D-F, new neoclerodane diterpenoids from Salvia divinorum, and an improved method for the isolation of salvinorin A. J Nat Prod 66:703-705

Ortega A, Blount JF, Manchand PD (1982) Salvinorin, a new transneoclerodane diterpene from Salvia divinorum (Labiatae). J Chem Soc Perkins Trans 1:2505-2508

Ott J (1995) Ethnopharmacognosy and human pharmacology of Salvia divinorum and salvinorin A. Curare 18:103-129

Ott J (1996) Salvia divinorum Epling et Játiva (Foglie della Pastora/ Leaves of the Sheperdess). Eleusis 4:31-39

Paulzen M, Grunder G (2008) Toxic psychosis after intake of the hallucinogen salvinorin A. J Clin Psychiatry 69:1501

Pavarin RM (2006) Substance use and related problems: a study on the abuse of recreational and not recreational drugs in Northern Italy. Ann Ist Super Sanità 42:477-484

Przekop P, Lee T (2009) Persistent psychosis associated with Salvia divinorum use. Am J Psychiatry 166:832

Roth BL, Baner K, Westkaemper R, Siebert D, Rice KC, Steinberg S, Ernsberger P, Rothman RB (2002) Salvinorin A: a potent naturally 
occurring nonnitrogenous kappa opioid selective agonist. Proc Natl Acad Sci USA 99:11934-11939

Siebert DJ (1994) Salvia divinorum and salvinorin A: new pharmacologic findings. J Ethnopharmacol 43:53-56

Singh S (2007) Adolescent salvia substance abuse. Addiction 102:823-824

Snyder SH, Faillace LA, Weingartner H (1968) DOM (STP), a new hallucinogenic drug, and DOET: effects in normal subjects. Am J Psychiatry 125:113-120

Substance Abuse and Mental Health Services Administration (2006) The NSDUH report-use of specific hallucinogens. NSDUH, Rockville

Tsujikawa K, Kuwayama K, Miyaguchi H, Kanamori T, Iwata YT, Yoshida T, Inoue H (2008) Determination of salvinorin A and salvinorin B in Salvia divinorum-related products circulated in Japan. Forensic Sci Int 180:105-109

Turek I, Soskin R, Kurland AA (1974) Methylendedioxyamphetamine (MDA) subjective effects. J Psychedelic Drugs 6:7-13

Valdés LJ 3rd (1983) The pharmacognosy of Salvia divinorum Epling \& Játiva-M: An investigation of Ska María Pastora. University of Michigan, (Ph.D. Thesis)
Valdés LJ 3rd, Butler WM, Hatfield GM, Paul AG, Koreeda M (1984) Divinorin A, a psychotropic terpenoid, and divinorin B, from the hallucinogenic Mexican mint, Salvia divinorum. J Org Chem 49:4716-4720

Valdés LJ 3rd, Hatfield GM, Koreeda M, Paul AG (1987) Studies of Salvia divinorum (Lamiaceae), an hallucinogenic mint from the Sierra Mazateca in Oaxaca, Central Mexico. Econ Bot 41:283291

Walsh SL, Strain EC, Abreu ME, Bigelow GE (2001) Enadoline, a selective kappa opioid agonist: comparison with butorphanol and hydromorphone in humans. Psychopharmacology (Berl) 157:151-162

Watson D, Clark LA, Tellegen A (1988) Development and validation of brief measures of positive and negative affect: the PANAS scales. J Pers Soc Psychol 54:1063-1070

Wolowich WR, Perkins AM, Cienki JJ (2006) Analysis of the psychoactive terpenoid salvinorin A content in five Salvia divinorum herbal products. Pharmacotherapy 26:1268-1272

Zhah (2009) Lost in Jonathan Ott's footsteps: acetone tinctures of salvia divinorum. Entheogen Review 16:132-136 